\title{
Applying the Kintsch-Van Dijk Model to Evaluate Impact on Foreign Language Learning: A Case Study
}

\author{
Ali Saleh Alghonaim* \\ College of Arabic Language and Social Studies, Qassim University, Saudi Arabia
}

Corresponding Author: Ali Saleh Alghonaim, E-mail: agniem@qu.edu.sa

\section{ARTICLE INFO}

Article history

Received: September 04, 2018

Accepted: November 25, 2018

Published: February 28, 2019

Volume: 10 Issue: 1

Advance access: January 2019

Conflicts of interest: None

Funding: None

\section{Key words:}

EFL learners, Case study, evaluation

\section{INTRODUCTION}

Reading is an important skill in learning English as a foreign language (EFL) (Al-Ahdal, \& Al-Ma'amari, 2015; Alfallaj, 2010). Modern theories of reading turned to smithereens the old beliefs that spelling out letters of a word or looking at them again and again is the way to learn to read. In reality, it is not individual letters that are 'seen' in isolation and then joined together by the reader, rather wholesome words and even phrases that are processed together. In other words, to be able to read well, one needs to 'see' longer bits of information and the mind needs to simultaneously make meaning out of what is read. A good reader, consequently, may overlook typo or other minor errors that do not interfere grossly with the meaning of the whole, indeed such errors may not even register with them. From almost the middle of the last millennium, reading has been variously described by language philosophers. To Webster (1982) reading is 'thinking under the stimulus of the printed page'. Gray (in Webster, 1982) defined reading as a three-tiered process: First, literal response to the graphic signals (ie the text); Second, recognition of the author's meaning; Third, reader's response to the text in the light of their personal experiences and judgements. It is, in fact, a complex and dynamic process, one which requires the involvement of the reader at many levels and needs them to put to use many faculties. These could be: 1. Knowledge of the graphemes; 2. An understanding of the three essentials of language viz, morphology, syntax, and semantics; 3. Sufficient ability to interpret the text; 4 . Awareness of the social context of the text.

This explains why Goodman (1967) calls reading a 'Psycholinguistic Guessing Game', one that involves selective use of syntactic, semantic and graphic language cues. What is significant to the current study is Goodman's claim that the reading process involves continuous use of long and short-term memory comprising of the reader's preconceptions and background knowledge. This may be explained by a simple example: When a doctor reads a medical text, he/she is likely to skip a great deal of medical terms without causing any distortion to the inference he/ she draws from the reading. However, the same text, when read by a non-medical person, would need to be read thoroughly and without skipping terms as doing so is likely to affect the understanding of the text. In the case of the doctor, the background knowledge is what allows them to skip sections while reading the text related to their field of study or work. In other words, the printed word is only a first step in the complex process of reading whereas the background knowledge is beyond the text, propositional and stored conceptually in the reader's long-term memory. This is also the opinion held by Garnham (1985) and Barnet (1988). It is for this reason that even if some words in a text are new and unknown to the readers, they may still be able to decode it. 


\section{Theoretical Framework}

Many models of reading have been suggested by thinkers from time to time. Urquhart and Weir (1998) classified all of these into two types: Process and Componential Models. Gough (1972) proposes that the reader starts with the letters which are decoded, phonemically placed, and finally uttered as a word. Thereafter, the reader moves on to the other parts of the sentence and so on. Goodman (1967) and Smith (1971) propose the reverse of this: The reader approaches the text with a hypothesis and the text helps them test this hypothesis. Rumelhart (1977) and Stanovich (1980) proposed the Interactive Approach. In this approach, the text is interpreted in the light of the reader's syntactical, lexical, semantic and orthographic knowledge. The interactive approach has been later expanded by some scholars (e.g., Paris, 2005; Sadoski \& Paivio, 2013; Urquhart \& Weir, 2014) to include the process and product of reading, coding of reading and writing and how development of reading among learners is interpreted. Hoover and Tummer (1993) proposed the Two-Component Approach which is based upon word recognition and linguistic comprehension of the text. This approach has been supported by several recent studies in examining reading comprehension among learners in different contexts (e.g., Bilikozen, \& Akyel, 2014; Høien-Tengesdal \& Høien, 2012; Kremmel, Brunfaut \& Alderson, 2015; Sabatini, Sawaki, Shore, \& Scarborough, 2015; Shiotsu \& Weir, 2007). Coady (1979) and Bernhardt (1991) claimed that not two but three factors were at play in case of reading: Conceptual abilities, process strategies and background knowledge. Just and Carpenter (1987) integrated both the Process and Componential Models. However, the most enduring and comprehensive of reading models is the Kintsch-Van Dijk Model on which the current study is based.

\section{About the Kintsch-Van Dijk Model of Text Comprehension and Production}

In 1978, Kintsch and Van Dijk presented the system of mental processes that lie at the base of reading comprehension, working memory, and micro and macro levels of breaking down the text into a semantic structure. According to those researchers, the process involves three levels of operations: First, the smaller units of meaning get organized into a coherent whole by multiple processing of some of the elements and retention of some in a memory hierarchy. Second, the gist of the whole is condensed. And third, most interestingly, the previous two operations generate new texts in working with the memory. In other words, the memory (both short term and long term, of the reader gives meaning to the text read. They propose three macro rules, viz., deletion, generalization, and construction as essential to reduce and organize the detailed information of the microstructure of the text. Further, schema is still predominant in the application of these macro-rules. In other words, previous knowledge and experience of the reader are still central to the interpretation of the text. Just as important as schema, is the word knowledge for the macro-rules to successfully operate. These two enable the reader to fill information gaps. Further, while reading, information is processed in chunks and this chunking is determined by sentence and phrase boundaries. Here short and long-term memory comeinto play, storing immediately unusable information for later recall. At the time of recall, it is not a random selection process that comes into play, but some selection strategy that employs an 'importance' principle, propositions belonging to a higher text-base hierarchy are recalled more efficiently than those belonging to the lower places on the hierarchy. Reader's knowledge base still plays a significant role in deriving the meaning of the text as with a lacking knowledge base, the same meaning will not be derived as that by one who has adequate knowledge base. Familiar text would require fewer resources for processing of the same. With familiarity, larger chunks of text are easily stored in the memory and more readily recalled. That the role of the reader is as central as the text itself is supported by the fact that readability is not a property of the text alone, but also of the text-reader interface.

Although the Kintsch-Van Dijk model deals primarily with the reader who is proficient with reading as such, that is one who can process all available information, putting aside the 'deviant cases', the current case study has chosen a non-native user of English as the participant as he has, over several years of language exposure, achieved proficiency that may be placed close to the native user. Further, in the peculiar EFL context and setting of the researcher, understanding the reading process of the EFL learner are more relevant for the benefit of the broad learner base.

\section{Review of Previous Literature}

Yaros (2006) interprets McNamara, Kintsch, Songer, \& Kitsch (1996) to imply that in the absence of previous knowledge to fill the gaps for the reader, the emphasis shifts wholly to textual explicitness for comprehension to take place.

Addison (2013) clearly states basing her view on Dijk and Kintsch, (1983) that local devices like coherence ties alone cannot get the reader to understand the discourse. Rather mental representation comes about only when there is 'global topic structure' in addition.

Bilki (2014) calls the proposition of Dijk-Kintsch as mental model theory, with focus on discourse processing. The theory is interpreted by the author to mean that comprehension involves integration of information from different parts of the text. Meaning is an outcome of the unique synthesis of meaning stated in the text and information stored in the long-term memory.

\section{Objectives of the Study}

This paper aims to evaluate post intervention using the Van Dijk model of comprehension whether they are effective in improving the literacy of a foreign language learner. In the long run, if found useful, the model can be applied for the advanced language learners as the skill to read and read with understanding can be a lifelong gift to them to enhance their language ability even outside the confines of the educational settings. 


\section{METHODOLOGY}

This is a case study of a Saudi twenty-year-old male student of English (not his mother tongue). The participant has had early English language exposure being from a private elementary school. This developed his interest in reading of English materials for pleasure. Initially, he read short stories and as his proficiency and comprehension improved, he moved to reading longer English texts. At the time of the study, the case student had discontinued with his prior pleasure reading practice and limited his English language exposure to two mandatory courses in English. His major is Marketing at Qassim University, College of Business and Marketing. The medium of education opted by him is also English.

\section{Rational for Text Selection}

Since the participant's reading interest had now shifted to business subjects, it was felt that an effective and pragmatic study of reading comprehension should include text bases in his focus area as he confided that he could not spare time for any other genre of reading given his curricular load. The text that he read for the first session was about business, his major. It is felt that though this study is restricted to one student, this rational of text selection might be significant to other students in other colleges or to students of relative level of language proficiency.

However, to establish a ground for my student level, I gave him a text that served as an introductory basis for the study. The first text he read was titled "Marriage on the Internet." This text dealt with a very common issue of general interest, marriage, and contained familiar words embedded in simple syntactical structures. There were very few new words for the participant. Even so, being fairly proficient and well into the habit of reading, he could guess the meaning of some of these words from the context. He managed to get mostly all the ideas of the text although the topic itself was new to him because he did not hear about marriage through the Internet due to the fact that "arranged marriage" is the prevalent norm in his country.

As per Van Dijk's (1982) theory, familiarity with the text is important so that there is some background knowledge readily available with the reader. Consequently, we chose this topic as related topics are often found favored by undergraduate learners in the environment during group discussions both inside and outside the classroom. The student was familiar with the text and propositional development of its ideas. Moreover, since the participant's vocabulary knowledge was good, he managed to initiate reading and was able to overcome the unfamiliarity of some words. In other words, the student was successful with regard to stage one of reading comprehension process; he provided a number of propositions mentioned in the reading task. For instance, he recognized most of the words and their meanings both at individual and contextual levels.

With the second text chosen for reading, although it was evident to the researcher that the language was higher in terms of difficulty and newness, the participant did not complain about the vocabulary items as much as he could not form clear ideas about the text base. The text related to his current area of study, ie., business studies. He pointed out that the problem was not with difficult words but with the content. He explained that each sentence included a piece of information. For more elaboration, the student was asked to provide a list of propositions from the text base. However, he could give just two sentences of general information about the text. He only mentioned two general thoughts that related to the topic itself and not to the ideas stated in the text base. However, when asking him to locate the key words in each paragraph, he did not identify any word. Yet, he could provide a list of concepts and ideas mentioned all through the text. For instance, when he was asked to summarize the first two paragraph, he gave some information that was relevant only to the title of the passage.

The participant was allowed another chance to read one paragraph carefully, but he could not comprehend it although he recognized all the words. He compared this paragraph, in particular, and the text, in general, with the first one and mentioned that he had to read all the sentences to understand the idea. On the other hand, in the first text, he just needed to read the first sentence of each paragraph to arrive at the central point.

\section{Implicit}

From the first introductory interview and the first reading session, it was evident that the participant possessed a good number of vocabulary items. This can be evidenced from the fact that he started learning English at an early age. Additionally, he used to spend a good amount of time reading stories to which he attributes the gaining of new vocabulary items. The description below is exclusively related to the second session in which the participant read the "business" text because, as mentioned earlier, this text represents the student's area of reading due to him majoring in business.

The student showed common features with the two texts that he read earlier. For example, he did not have any problem with specific vocabulary. Although the difficulty level of the two texts varied, the participant was able to understand most words. Earlier the participant could not locate any key word or difficult words in the first readings. This showed that he didn't have problems with stage one.

When the participant was asked to provide the main ideas mentioned in the text, he resorted to his background knowledge and provided relative information but not specific to the text base, as mentioned above. This is because he either did not comprehend the text or that his working memory did not help him retrieve the information. However, he was given another opportunity to reread another paragraph. He was asked to instantly explain it or paraphrase it, but he could not form a clear idea about it although he recognized most of the words. This showed that the student had a problem with getting a connected discourse from the text base, which relates to stage two of Van Dijk comprehension model.

\section{Intervention}

The aim of this part is to provide an intervention to the participant who struggles with reading comprehension. The in- 
terventional technique that will be used here is based on the outcome of his evaluation through several settings of observations and activities. Although the interventional technique used here is not new to any student, it reflects what the participant or any other student needs to do in order to overcome the problems with reading comprehension. In other words, this activity is not just chosen for the sake of using a different technique. Rather, this intervention is used with this student in this particular situation of reading comprehension problem that was discussed thoroughly in the evaluative section. The type of the interventional technique is briefly provided later below.

The main problem that the participant student struggles with throughout the study relates to comprehending the basic meanings of the textual information. Specifically, he is almost aware of the individual and literal meanings of words. However, he hardly forms a complete and correct meaning for himself. This is mainly because he reads for a required purpose, reading for the class or preparing for the exam in which information is of priority. Therefore, he brings his attention to every single word and thus puts himself into high level of anxiety where he feels attached to one meaning that may not harmonize with the rest of the sentence. As a result, he becomes unable to think of other meanings of particular words although he knows them which causes either wrong decoding or inability to understand the intended information.

From observation, this issue of focusing mainly on every word or sentence as being essential to the whole text caused a major problem to him as many words have more than one basic meaning in addition to other secondary meanings. In several cases, he tried to employ one meaning of a word to a sentence where this word was used for another relative meaning that he did not think of. Consequently, this caused a comprehension problematic to him because he does not skip unfamiliar or unclear words so that he might guess the probable meaning of unclear or confusing words after reading the whole text or the whole paragraph. Rather, he focuses on the meaning of every single word.

Based on these findings, the participant was set to two interventional activities. One of these was intended to tackle the first problem related to the attachment of the participant to one source of information presented in the text. He was given one source of information and then given another source that tackled the same issue presented in the reading text. This technique aimed at reading the same issue from a different perspective or by the means of different words. The other interventional technique that the participant did related to the problem of focusing on every word and not skipping unfamiliar or confusing words for later guesses. For this problem, he was asked to read the whole text or paragraph and underline the key and confusing words. Later, he was asked to go back again and, guess the meaning of these words after finishing the reading and not during the reading. This might imply that he read the text again and guessed afterwards. This technique aimed at creating a considerable contextual background to help and encourage him to make his guesses.

The idea behind the use of two techniques for relatively one problem of reading comprehension, i.e., informational comprehension, is that sometime even when the student reads the whole text or paragraph, he cannot make the right guess when rereading it again. Therefore, resorting to another source of information seemed presumably beneficial to the participant's case.

Expectedly, the participant will be able to approach the same information in different word groups and from a different angle which will probably help him gain more understanding when reading the required text. This is so because the reader is predisposed to bring another informational knowledge to the text that is likely to enhance him to globally deal with the text base. This is also useful because the reader will probably be able to provide himself with similar information that helps him approach the text without much anxiety. Finally, this technique is assumed to provide confidence to the participant student since he is likely expected to find the same information which confirms to her that the information is the same in a different resource, especially, in his major of marketing where knowledge and terms are widely shared.

\section{RESULTS PRODUCED POST-INTERVENTION: CONCLUSIONS}

\section{First Activity}

The participant read a text in his major, marketing. This text was included in the class for the final exam. This text contained some terms that he did not know. For example, he ran into a term called 'value chain'. He did not understand the meaning of this term although it was briefly explained. He described the text and the definition of the term as abstract. He also was misled by what he called the "physical" meaning of the word "value." Although he was aware of the other meanings of it, he understood that it meant "money" or "gold." He also pointed out that the textual language was hard to follow although he knew mostly all of the words.

Later, the participant read another text relatively about the same term presented in a different way. The participant stated that the information in the second text was supported by extra examples and figures. Furthermore, he posited that the second text provided him with specific schemata that expanded his comprehension of the first text because the word "value" was presented in a different way with the meaning of "importance", or "significance," which meant the same thing in the first text.

After finishing the second text, the participant reported that the reading of the first text became "smooth." He kept referring to the two texts back and forth. It seems that the two texts provided reciprocal knowledge that supported each other because he did not find any contradiction between the pieces of information displayed in the two texts. However, he reported that although this technique is useful, it is time consuming. He also stated that he might not be able to find another resource that discusses relatively the same topic. This, as stated above, justified the combination of this technique with the second one.

\section{Second Activity}

The other interventional technique was aimed to help him arrive at the intended meaning of the information. He read a 
paragraph which contained a term of "usability testing." The paragraph proceeded by defining this term. The participant did not fully understand the definition although he was familiar with the vocabulary items. As explained in the technique proposal, he was asked to guess for the misleading words. However, most importantly, he was asked to keep reading and, while reading, he was asked to underline the difficult words and to delay any guess until reaching the end of the paragraph. He, again was asked to read the same paragraph in which he was asked to make guesses to the words he felt no comprehendible to him. The aim of this technique was not only to guess but also to enhance guessing. The tutor explained the goal of this intervention to the participant; therefore, he told him if he wanted to read the text again before making any guess. However, when the participant started to make guesses, noticeably, he did not guess all the words that he underlined. He reported that he either did not need to do so or forgot because they were not as important as before.

He further reported that he had never tried this technique before. He felt more confident about his guesses as he stated that sometimes he understood the intended meaning without even guessing for the other words. The participant also felt that delaying the guesses for after reading the whole text provided him with extra about the local meaning. In other words, he believed that when making guesses after just reading the sentence that contained the unfamiliar words might limit his guesses mainly to the very local meaning which might make it difficult and narrow or to make the right guess. But reading the whole text would probably expand his perception of the words and the content which helps lead him to arrive at the appropriate guess.

Thus, the result amply supported the model proposed by Kintsch and Van Dijk. It appears that familiarity with the text aided by sufficient background knowledge can enhance the reading comprehension even in the case of foreign language learning. Of course, the precondition is the presence of sufficient vocabulary in the reader. Further, even given the fact that adequate background knowledge is missing, repeatedly reading a text can create a temporary but useful background information bank against which the previously unfamiliar text can be successfully decoded.

\section{REFERENCES}

Addison, M. (2013). Mental models in discourse production: Atypical discourse and the role of event models in the narratives of depressed patients. Master's thesis submitted to Carleton University, Ontario. https://curve. carleton.ca/system/files/etd/ea492dfb-05a2-42af-87c63487ce48eeef/etd_pdf/cda4f163dea7a45e11727ea699da408b/addison-mentalmodelsindiscourseproduction.pdf Al-Ahdal, A. A. M. H., \& Al-Ma'amari, A. A. H. (2015). Learning Strategies of the Arab EFL Learners: Finding Correlation with Outcomes. Advances in Language and Literary Studies, 6(5), 230-241. 10.7575/aiac. alls.v.6n.5p. 230

Alfallaj, F.S.S. (2010). Reading competence of the Saudi EFL learner: Improving the teacher through linguistics. Australian International Academic Centre, Australia, 8(3),12-17.
Barnet, M. (1988). Teaching Reading Strategies: How methodology affects course articulation. Foreign Language Annals. Vol. 21, issue 2, pp. 109-119. https://onlinelibrary.wiley.com/doi/abs/10.1111/j.1944-9720.1988. tb03119.x, accessed 28 January 2019.

Bernhardt, E.B. (1991). A psycholinguistic perspective on Second language literacy. In Hulstijn, 1.H. and Matter, 1.F. (eds.) Reading in two languages. AILA Review, vol.8 (Amesterdam) (pp.31-44).

Bilki, Z. (2014). A Close Observation of second language (L2) readers and texts: meaning representation and construction through cohesion. Doctoral thesis submitted to University of Iowa. https://ir.uiowa.edu/ cgi/viewcontent.cgi?referer=https://www.google. com $/ \&$ httpsredir $=1 \&$ article $=5332 \&$ context $=$ etd

Bilikozen, N., \& Akyel, A. (2014). EFL reading comprehension, individual differences and text difficulty. Reading, 14(2), 263-296. https://eric.ed.gov/?id=EJ1046909.

Coady, J. (1979) A Psycholinguistic Model of the ESL Reader. In: Ronald, M. and Bruce, B., Eds., Reading in a Second Language, Newbury House Publishers, Rowley, 5-12.

Garnham, A. (1985). Psycholinguistics: Central Topics. New York: Metheun.

Goodman, Kenneth S. (1967). Reading: A psycholinguistic guessing game. Journal of the Reading Specialist. 6. 126-135.

Gough, P. B. (1972). One second of reading. In J. F. Kavanagh \& I. G. Mattingly (Eds.), Language by ear and by eye: The relationship between speech and reading. Oxford, England: Massachusetts Inst. of Technology P.

Hoover, W. A., \& Tunmer, W. E. (1993). The components of reading. In G. B. Thompson, W. E. Tunmer, \& T. Nicholson (Eds.), Language and education library, 4. Reading acquisition processes (pp. 1-19). Clevedon, England: Multilingual Matters.

Høien-Tengesdal, I., \& Høien, T. (2012). The reading efficiency model: An extension of the componential model of reading. Journal of Learning disabilities, 45(5), 467-479. https://journals.sagepub.com/doi/ abs/10.1177/0022219411432688.

Just, M. A., \& Carpenter, P. A. (1987). The psychology of reading and language comprehension. Newton, MA: Allyn \& Bacon.

Kremmel, B., Brunfaut, T., \& Alderson, J. C. (2015). Exploring the role of phraseological knowledge in foreign language reading. Applied Linguistics, 38(6), 848-870. https://academic.oup.com/applij/article/38/6/848/2952213.

Paris, S. G. (2005). Reinterpreting the development of reading skills. Reading research quarterly, 40(2), 184-202. doi:10.1598/RRQ.40.2.3.

Rumelhart, D. E. (I 977b). Toward an interactive model of reading. In S. Domic (Ed.) Attemion and performance VJ (pp. 573- 603). Hillsdale, NJ: Erlbaum.

Sabatini, J. P., Sawaki, Y., Shore, J. R., \& Scarborough, H. S. (2010). Relationships among reading skills of adults with low literacy. Journal of learning disabilities, 43(2), 122-138. https://www.ncbi.nlm.nih.gov/pmc/articles/ PMC3269070/. 
Sadoski, M., \& Paivio, A. (2013). Imagery and text: A dual coding theory of reading and writing. Routledge. https:// doi.org/10.4324/9780203801932.

Shiotsu, T., \& Weir, C. J. (2007). The relative significance of syntactic knowledge and vocabulary breadth in the prediction of reading comprehension test performance. Language Testing, 24(1), 99-128. https://doi. org/10.1177/0265532207071513.

Smith, F. (1971). Understanding Reading. New York: Holt, Rinehart and Winston. The Reading Specialist, 6, 126135. doi:10.1080/19388076709556976
Urquhart, A \& Weir, C (1998). Reading in a Second Language: Process, Product and Practice, London: Longman, pp.1-7; 37-51.

Urquhart, A. H., \& Weir, C. J. (2014). Reading in a second language: Process, product and practice. Routledge. https://www.taylorfrancis.com/books/9781317885689.

Webster, J. (1982). Reading Matters. A Practical Philosophy. London: McGraw Hill Book Company (UK) Ltd.

Yaros, R. A. (2006). Is it the medium of the message? Structuring Complex News to Enhance Engagement and Situational Understanding by Nonexperts. Communication Research. 33(4). 